\title{
CONDICIONANTES GEOAMBIENTAIS DA LOCALIZAÇÃO DA INFRAESTRUTURA PORTUÁRIA, FAROLEIRA, MILITAR E BALEEIRA DA ILHA DE SANTA CATARINA
}

Washington Ferreira ${ }^{1}$

\section{Resumo}

Procurou-se estabelecer uma aproximação entre a História Ambiental e o Gerenciamento Costeiro, para a análise do papel dos condicionantes geoambientais na seleção dos sítios para a instalação da infraestrutura de um conjunto de atividades socioeconômicas interligadas (navegação, defesa, caça a baleia e comércio portuário), na llha de Santa Catarina, SC, Brasil. Nesta aproximação, promoveu-se a sobreposição de três camadas de informação (cartas náuticas, mapas temáticos ambientais, vestígios arqueológicos) em um sistema de informações geográficas, simultaneamente a análise documental de uma série de fontes históricas sobre as referidas atividades socioeconômicas na região, estabelecendo as correlações entre as mesmas e os parâmetros definidos como condicionantes geoambientais de sua localização.

Palavras-chave: condicionantes geoambientais, atividades socioeconômicas, Ilha de Santa Catarina.

\section{Resumen}

Se trató de establecer una conexión entre la Historia Ambiental y el Manejo Costero Integrado, para analizar el papel de las condiciones geo-ambientales en la selección de sitios para la instalación de la infraestructura de un conjunto de actividades socioeconómicas interconectadas (navegación, la defensa, la caza de ballenas y el puerto), en la isla de Santa Catarina, Santa Catarina, Brasil. En este enfoque, promovido por la superposición de tres capas de información (gráficos, mapas temáticos ambientales, restos arqueológicos) en un sistema de información geográfica, mientras que el análisis documental de una serie de fuentes históricas sobre las actividades socio-económicas de la región, estableciendo las correlaciones entre ellos y los parámetros definidos como condiciones geo ambientales de su ubicación.

Palabras-clave: condiciones geo ambientales, actividades socioeconómicas, la isla de Santa Catarina.

\begin{abstract}
We tried to establish a connection between Environmental History and Coastal Management, to analyze the role of geo-environmental conditions in the selection of sites for the installation of the infrastructure of a set of interconnected socioeconomic activities (navigation, defense, hunting the whale and port trade), on the island of Santa Catarina, Santa Catarina, Brazil. In this approach, promoted up the overlapping of three layers of information (charts, environmental thematic maps, archaeological remains) in a geographic information

\footnotetext{
${ }^{1}$ Bacharel em Oceanografia (Dezembro/1995), Mestre em Oceanografia Biológica (Maio/2004) e Doutor em Educação Ambiental (Agosto/2014) pela FURG - Universidade Federal do Rio Grande, RS. Pós-Doutor em
} Geografia (Agosto/2015) pela UFSC - Universidade Federal de Santa Catarina, SC.
\end{abstract}

(C) Rev. Arqueologia Pública \begin{tabular}{l|l} 
Campinas, SP & v.9
\end{tabular} No.(11) p.93-104 suplemento 
system, while the documentary analysis of a number of historical sources on those socioeconomic activities in the region, establishing the correlations between them and the parameters defined as geo-environmental conditions of its location.

Keywords: geo-environmental conditions, socioeconomic activities, the island of Santa Catarina.

\section{Introdução}

Ao longo do seu processo de desenvolvimento, a llha de Santa Catarina (Florianópolis, $\mathrm{SC}$, Brasil), passou por diversas etapas históricas e políticas, nas quais as suas características geoambientais condicionaram a localização das atividades socioeconômicas preponderantes. Neste trabalho, são analisados e discutidos os condicionantes geoambientais da localização da infraestrutura de uma série de atividades costeiras, como obras portuárias, faroleiras, militares e baleeiras, através da análise espacial dos seus respectivos vestígios arqueológicos.

Tais estruturas, por localizarem-se sobre a linha de costa, podem constituir-se em elementos indicativos de alguns dos condicionantes geoambientais que justificaram sua instalação neste território insular. Dentre estes condicionantes, destacam-se aqueles relativos à posição geográfica (coordenadas, clima), a tipologia de ambientes (costões rochosos, praias arenosas, restingas, manguezais), condições meteoro-oceanográficas (profundidade, substrato, orientação em relação ao regime de ventos, marés e correntes), tipologia dos terrenos (topografia, altitude, tipo de solo), acessibilidade (rotas de navegação, estradas), disponibilidade de recursos naturais para subsistência e reabastecimento de embarcações (água, alimentação, lenha) e para construção das edificações (areia, cascalho, cal, pedras, argila, madeira).

\section{Procedimentos Metodológicos}

Procedeu-se a uma aproximação entre a História Ambiental (PÁDUA, 2010) e o Gerenciamento Costeiro (POLETTE et al., 2006), para a inferência sobre o papel dos condicionantes geoambientais na localização da infraestrutura das atividades socioeconômicas, utilizando-se como Estudo de Caso (YIN, 2005), a Ilha de Santa Catarina. Esta aproximação decorreu da sobreposição de três camadas de informação (cartas náuticas 
$\mathrm{DHN}^{2}$, mapas temáticos ambientais, vestígios arqueológicos) em um sistema de informações geográficas, simultaneamente a análise documental de uma série de fontes históricas sobre as referidas atividades socioeconômicas (navegação, defesa, caça a baleia e comércio portuário) na região, estabelecendo as correlações entre as mesmas e os parâmetros definidos como condicionantes geoambientais de sua localização.

\section{Resultados e Discussão}

Ao longo do seu desenvolvimento sociocultural e político-econômico, a llha de Santa Catarina, sede da vila de Nossa Senhora do Desterro (atual município de Florianópolis), passou por diversas etapas, nas quais houve o predomínio de algumas atividades, com a progressiva substituição de outras; para a efetividade destas atividades, foram construídas diversas estruturas, das quais ainda dispomos de vestígios arqueológicos elou de informações históricas.

Estas atividades podem ser entendidas enquanto processos produtivos, funções ou tecnologias, porque os efeitos paradoxais gerados pelas tecnologias não são consequências incidentais, mas antes mecanismos sistematicamente conducentes ao emprego de mais tecnologia (FOX et al., 2008: 75). As atividades socioeconômicas elencadas neste estudo (portuária, faroleira, militar e baleeira) combinam duas características geopolíticas: inserem-se no contexto das funções de domínio e segurança do território e demandam infraestruturas edificadas na linha de costa, além de complementarem-se mutuamente. Como tais, seus vestígios arqueológicos são constructos que permitem a engenharia reversa do processo de decisão sobre os critérios para a localização destas categorias de atividades.

As feições específicas das áreas onde tais atividades são instaladas estão associadas ao respectivo contexto geográfico onde as mesmas se localizam; este contexto geográfico modela a estrutura e a fisionomia das paisagens:

Estas variadas paisagens possuem valor incalculável e são muitas vezes ameaçadas em sua estabilidade por intervenções antropogênicas ou por causas naturais associadas a variações climáticas e, consequentemente, a variações relativas do nível do mar. A responsabilidade de formação e manutenção desta ampla linha de costa é prioritariamente associada a três fatores, que atuaram e atuam em várias escalas temporais e espaciais: a herança geológica, o

\footnotetext{
${ }^{2}$ Publicações oficiais da DHN - Diretoria de Hidrografia e Navegação, da Marinha do Brasil, condensando as informações sobre a localização, batimetria, correntes, ventos e marés, de cada região do país.
}

(C) Rev. Arqueologia Pública

\begin{tabular}{l|l|} 
Campinas, SP & v.9
\end{tabular}

No.(11)

p.93-104

suplemento

ISSN 2237-8294 
modelado quaternário e a ação da dinâmica sedimentar atual (TESSLER, GOYA, 2005: 11).

A costa brasileira possui uma série de elementos climáticos, oceanográficos e geomorfológicos que condicionam os processos atuantes. Entre Cabo Frio (RJ) e Cabo de Santa Marta (SC), o litoral é caracterizado pela presença da Serra do Mar, constituída por rochas do Embasamento Cristalino que afloram continuamente neste trecho com alinhamento aproximadamente paralelo à linha de costa. Neste setor, o litoral de Santa Catarina (ao sul da baía de São Francisco do Sul) tende a ser recortado, com vários pontos onde a Serra atinge diretamente a linha de costa (TESSLER, GOYA, 2005: 16-18).

Segundo a perspectiva dos estudos arqueológicos, os sítios históricos da llha de Santa Catarina podem ser classificados de acordo com suas funções (OLIVEIRA e SYMANSKI apud COMERLATO, 2003: 04), como sítios religiosos (cemitérios, igrejas), sítios militares (baterias, fortalezas, fortes e fortins), sítios comerciais/produtivos (armações, engenhos, caieiras, indústrias), sítios domésticos (residências, sesmarias), sítios portuários (alfândega, cais, portos), entre outros (como caminhos e quilombos). E também classificados de outra forma como, por exemplo, macrorregiões (COMERLATO, 2003: 05, apud SCHUCH, 2010: 24).

A sucessão ou complementariedade das atividades portuárias, faroleiras, militares e baleeiras na llha de Santa Catarina e os respectivos condicionantes geoambientais podem ser melhor compreendidos pela sua distribuição temporal e as infraestruturas necessárias (Tab. 01).

Tabela 01: Infraestruturas e condicionantes geoambientais na llha de Santa Catarina

\begin{tabular}{|c|c|c|c|}
\hline $\begin{array}{l}\text { Etapas } \\
\text { Históricas }\end{array}$ & Atividades & Estruturas & Condicionantes \\
\hline $\begin{array}{l}\text { Pré- } \\
\text { Colonial } \\
(1494- \\
1640)\end{array}$ & $\begin{array}{l}\text { Abrigo e Fundeadouro de } \\
\text { embarcações de passagem. } \\
\text { Reabastecimento (de água, víveres e } \\
\text { madeiras). }\end{array}$ & Portos naturais. & $\begin{array}{l}\text { Enseadas } \\
\text { protegidas do mar } \\
\text { aberto. }\end{array}$ \\
\hline $\begin{array}{l}\text { Colonial } \\
(1641- \\
1756)\end{array}$ & $\begin{array}{l}\text { Abrigo e Fundeadouro de } \\
\text { embarcações de passagem e frota de } \\
\text { defesa. } \\
\text { Produção de subsistência (pesca e } \\
\text { agricultura). Caça a baleia. Defesa, } \\
\text { Ocupação (colonos açorianos). }\end{array}$ & $\begin{array}{l}\text { Estruturas } \\
\text { portuárias e } \\
\text { alfandegárias. } \\
\text { Armações baleeiras. } \\
\text { Fortalezas militares. }\end{array}$ & $\begin{array}{l}\text { Enseadas } \\
\text { protegidas do mar } \\
\text { aberto. Mirantes } \\
\text { para observação } \\
\text { dos cetáceos, } \\
\text { proximidade do mar } \\
\text { aberto. } \\
\text { Atracadouros }\end{array}$ \\
\hline
\end{tabular}

(C) Rev. Arqueologia Pública \begin{tabular}{l|l} 
Campinas, SP & v.9
\end{tabular} No.(11) p.93-104 suplemento ISSN 2237-8294 


\begin{tabular}{|c|c|c|c|}
\hline & & & $\begin{array}{ll}\text { seguros, } & \text { controle } \\
\text { dos } & \text { acessos } \\
\text { náuticos. } & \end{array}$ \\
\hline $\begin{array}{l}\text { Guerras } \\
\text { Regionais } \\
(1757- \\
1900)\end{array}$ & $\begin{array}{l}\text { Abrigo e } \text { Fundeadouro de } \\
\text { embarcações de passagem e frota de } \\
\text { defesa. } \\
\text { Extrativismo, produção agrícola } \\
\text { comercial e de Exportação. Produtos } \\
\text { semi-industrializados. }\end{array}$ & $\begin{array}{l}\text { Estruturas } \\
\text { portuárias } \\
\text { alfandegárias. } \\
\text { Atracadouros } \\
\text { trapiches para carga } \\
\text { e descarga. } \\
\begin{array}{lr}\text { Depósitos } & \text { de } \\
\text { produtos. } & \text { Faróis } \\
\text { náuticos. }\end{array}\end{array}$ & $\begin{array}{l}\text { Profundidade } \\
\text { adequada ao calado } \\
\text { das embarcações. } \\
\text { Conexões com rede } \\
\text { de transportes. } \\
\text { Mirantes para } \\
\text { sinalização náutica } \\
\text { as embarcações. }\end{array}$ \\
\hline $\begin{array}{l}\text { Grandes } \\
\text { Guerras } \\
(1901- \\
1945)\end{array}$ & $\begin{array}{l}\text { Abrigo e Fundeadouro de } \\
\text { embarcações de passagem. Ligação } \\
\text { com o continente. Perda da } \\
\text { produtividade. Colapso da produção } \\
\text { Comercial e de Exportação. Expansão } \\
\text { urbana, construção civil. Cidade } \\
\text { Administrativa, Turismo e balneários. }\end{array}$ & $\begin{array}{l}\text { Decadência do } \\
\text { porto. Construção } \\
\text { da ponte. Produção } \\
\text { Comercial e de } \\
\text { Exportação } \\
\text { remanescente. }\end{array}$ & $\begin{array}{l}\text { Progressivo } \\
\text { assoreamento } \\
\text { natural das baías } \\
\text { Início dos aterros } \\
\text { antropogênicos das } \\
\text { baías. }\end{array}$ \\
\hline $\begin{array}{l}\text { Pós- } \\
\text { Guerra } \\
(1946 \gg>)\end{array}$ & $\begin{array}{l}\text { Abrigo e Fundeadouro (navegação de } \\
\text { recreio), saneamento básico. } \\
\text { Maricultura. Expansão de área } \\
\text { urbana. } \\
\text { Alteração da linha de costa e praias } \\
\text { (erosão), Administrativa (sede de } \\
\text { Cidade Admina serviços públicos), } \\
\text { empresas e (loteamentos e } \\
\text { Turismo e balneários (lomosion). } \\
\text { condomínios) }\end{array}$ & $\begin{array}{lr}\text { Conversão } & \text { para } \\
\text { turismo } & \text { náutico. } \\
\text { Redução } & \text { da } \\
\text { produção Comercial } \\
\text { e de Exportação } \\
\text { remanescente. }\end{array}$ & $\begin{array}{l}\text { Incremento dos } \\
\text { aterros das baías. } \\
\text { Pequenas áreas } \\
\text { para clubes náuticos } \\
\text { e empresas de } \\
\text { transporte marítimo. } \\
\text { Baías usadas para } \\
\text { maricultura. }\end{array}$ \\
\hline
\end{tabular}

Atividades Portuárias: nesta categoria, reúnem-se diversas etapas e atividades específicas, indispensáveis à navegação, segurança e comércio náutico:

a) Portos Naturais, representados pelas ótimas condições geográficas, como abrigos com boas condições de fundeio (substrato e profundidade adequada ao calado das embarcações), protegidos das condições adversas do vento e do mar (baías), amplamente utilizados pelos navios e esquadras que percorriam a costa sul americana ${ }^{3}$.

\footnotetext{
${ }^{3}$ Em março de 1712, o engenheiro militar Améde Frézier (procedente de Saint Malo, França), ancorou na Ilha e fez um esboço para um mapa local; em 1796, foram registradas 116 embarcações de passagem (CARUSO, 1983: 41; 79).
} 
b) Reabastecimento de Embarcações, como primeira atividade socioeconômica reconhecida da llha de Santa Catarina, as embarcações de passagem pela região necessitavam de reabastecimento de água potável (fazer aguada), víveres e madeiras ${ }^{4}$.

c) Estruturas Portuárias e Alfandegárias: estas operações exigem serviços de atracação (fundeadouros, piers e trapiches), reabastecimento (de água, víveres e combustíveis), armazenagem (depósitos de produtos) e cobrança de tributos nas imediações 5 . O prédio da Alfândega foi construído bem próximo ao mar, em 1875, sendo muito importante para o desenvolvimento econômico do Império, para guardar os produtos que seriam exportados e também importados (VEIGA, 1993, apud $\mathrm{SCHUCH,} \mathrm{2010:} \mathrm{30).} \mathrm{O} \mathrm{salvamento}$ arqueológico ocorreu em duas partes: o primeiro cais (construído por volta de 1876) e o segundo cais (com datação em aberto); o primeiro cais foi aterrado para a construção do segundo (AMARAL, 1992, p. 24). Dois pilares de madeira foram encontrados, que provavelmente faziam parte da estrutura do trapiche.

Este tipo de trabalho é importante, por oferecer informações sobre as técnicas construtivas de áreas portuárias (SCHUCH, 2010: 32). No bairro Rita Maria, antiga zona portuária e do primeiro ciclo industrial da cidade, situavam-se os prédios dos antigos armazéns portuários; área esta também aterrada na década de 1970. No seu monitoramento arqueológico, foi encontrada parte de uma estrutura semelhante à localizada frente à antiga alfândega na década de 1990 (SCHUCH, 2010: 78-79).

d) Estaleiros: serviços de construção e manutenção de embarcações pesqueiras, mercantes e bélicas. Em 1870, ainda existiam 03 estaleiros no Desterro, um na Prainha, outro na Praia de Fora, e um próximo do trapiche Rita Maria (SANTOS, 2005: 13), o célebre "Arataca" 6.

\footnotetext{
${ }^{4} \mathrm{Em} \mathrm{1526}$, Sebastião Caboto permaneceu na llha durante quatro meses, construindo uma galeota (CARUSO, 1983: 79); George Shelvocke (capitão do navio inglês "Clipperton") aportou na llha em junho de 1719, descrevendo os pontos de aguada, abastecimento de madeira e víveres (BERGER, 1984: 19).

${ }^{5}$ Em 1906, foi estabelecido um posto fiscal aduaneiro junto ao atracadouro da "ilha" da Ponta do Sambaqui, utilizando uma edificação construída em 1854 (SCHMITZ, 2014: 04-05). O Porto do Contrato somava a função de entreposto de pescados, lenha, café, produtos da Armação da Lagoinha, e da Freguesia do Ribeirão da Ilha (ESPÍNDOLA, 2010: 79). O prédio da alfandega foi construído em 1875, com um cais, que avançava mar adentro (VEIGA, 1993: 09), para facilitar o acesso de passageiros e mercadorias, assim como o "Miramar", construído em 1928 (ALMEIDA, 2008: 22).

6 Em 1907, Carl Hoepcke construiu o estaleiro "Arataca", próximo ao Forte Santana; era formado por várias edificações e de uma carreira para os navios; manteve-se atuante até a década de 1940 (DESTERRO HOJE, 2014).
} 
O Porto de Florianópolis: nos meados do século XIX, a elite do Desterro era constituída de comerciantes e armadores (REIS, 2012: 61); durante todo o século XIX e início do XX, este porto escoava grande parte da produção agrícola regional (farinha, a aguardente, ao açúcar e a madeira), com a progressiva especialização dos portos catarinenses: Florianópolis (farinha), Laguna e Imbituba (carvão), Itajaí (derivados de suínos), e São Francisco (erva-mate e madeira) (GOULARTI FILHO, 2013: 20). A inauguração da ponte Hercílio Luz (1926) marcou o início da decadência do porto de Florianópolis, devido a sua pequena profundidade e progressivo assoreamento, como às mudanças macroeconômicas, a partir da década de 1920, dentre elas, a substituição do transporte marítimo e ferroviário pelo transporte rodoviário.

As características naturais da llha de Santa Catarina foram amplamente favoráveis a sua utilização para as funções de porto de passagem e reabastecimento de embarcações no período pré-colonial e colonial, e como porto exportador de gêneros agrícolas e pesqueiros até meados do século XX. Contudo, o progressivo assoreamento das suas baías e o concomitante processo de substituição dos modais ferroviários e náuticos pelas autoestradas determinou a rápida obsolescência das atividades portuárias locais. Atualmente, a região substituiu as operações de carga e descarga de produtos pela navegação de recreio, as quais não necessitam de grande calado, mas que também tem os seus condicionantes e perigos:

O acesso ao porto da llha de Santa Catarina, por qualquer canal, só deve ser feito por navegante que tenha perfeito conhecimento da área, que é muito assoreada e apresenta inúmeras pedras submersas. $O$ canal de acesso foi dragado pela última vez em 1954, razão pela qual não há segurança para o tráfego de embarcações com calado acima de $2,5 \mathrm{~m}$ (8 pés), na preamar. Nos dois canais de acesso e na área em frente aos atracadouros há um grande número de pedras submersas, isoladas ou junto das ilhas e da costa. O constante assoreamento de toda a área entre a ilha de Santa Catarina e o continente requer, do navegante que for demandar a região por qualquer barra, um perfeito conhecimento local. As embarcações podem fundear nas baías Norte e Sul, em fundos de $6 \mathrm{~m}$, lama. Em qualquer situação, não há abrigo para os ventos dos quadrantes norte, oeste e sul. Deve ser evitado o fundeio em frente aos atracadouros situados entre as duas pontes, até a distância de 600m (DHN, 2013: 209-210).

Caça a Baleia: foram instaladas "armações" baleeiras em diversos pontos da costa de Santa Catarina, como Piedade (Anhatomirim, 1740), Lagoinha (Pântano do Sul, 1772), Itapocorói (Penha, 1778), Ilha da Graça, Garopaba e Imbituba. A seleção de áreas para sua 
instalação atendia a critérios associados com a proximidade relativa aos locais de avistagem (mirantes) e captura (áreas de alimentação) de cetáceos, bem como a tipologia de praias adequadas ao lançamento das embarcações (movidas a remo). Em relação às formas e estruturas das instalações destas "Armações" no litoral de $\mathrm{SC}^{7}$, vale relembrar que estas adotaram a "adaptação à morfologia das praias (prolongamento de praias em pontais, linhas de praias construídas, e dois patamares distintos) e o agrupamento segundo sua funcionalidade" (MUSSOLINI, 1953: 81).

Fortalezas Militares: sob o comando do Brigadeiro José da Silva Paes, iniciaram-se as obras de construção do complexo militar regional (1738-1742). Priorizando o controle do acesso à capital pelas embarcações, estas estruturas foram concentradas na Baía Norte (Santa Cruz, na Ilha de Anhatomirim; São José da Ponta Grossa, em Jurere; São Caetano e Santo Antônio de Ratones, na llha de Ratones Grande; São Luiz e São Francisco Xavier, na Praia de Fora, Desterro) e na Baía Sul (Nossa Senhora da Conceição de Araçatuba, na llha de Araçatuba; Marechal Moura, na Praia de Naufragados), três estruturas na área central (Sant'Anna e Santa Bárbara, na llha; São João, na porção continental), bem como outra, junto à barra da Lagoa da Conceição (Nossa Senhora da Conceição). Já no século XX, entre 1909 e 1913, construiu-se o Forte Marechal Mouro, hoje em ruínas, junto ao Farol de Naufragados, no sul da llha de Santa Catarina (TONERA, 2007: 05).

O trabalho arqueológico no Forte Santana foi realizado em 1999, com o objetivo de recuperação de vestígios arqueológicos (louças, vidros e outros fragmentos) na praia localizada abaixo do forte, por causa da ação das marés, após a recente construção de um trapiche para o corpo de bombeiros (COMERLATO, 1999: 03). Em 2002, notícias foram divulgadas sobre a ação das marés que estava ocorrendo no Forte Santana e que isso poderia prejudicar sua estrutura (SCHUCH, 2010: 38-39). Na baía norte, próximo ao Shopping Beira Mar (entre a Av. Mauro Ramos e a Av. Beira Mar): durante as obras de infraestrutura, foram localizados vestígios arqueológicos (louça, vidro e metal), que sugerem ser do antigo Forte São Luis, uma fortificação do século XVIII, utilizada para proteção da costa (SCHUCH, 2010: 62).

\footnotetext{
${ }^{7}$ A caça a baleia no litoral de SC entraria em decadência, a partir de 1830, pela concorrência da frota industrial norte-americana e a sobre explotação dos estoques.
}

(C) Rev. Arqueologia Pública

\begin{tabular}{l|l|} 
Campinas, SP & v.9
\end{tabular}

\begin{tabular}{|l|l|l|} 
No.(11) & p.93-104 & suplemento
\end{tabular}

ISSN 2237-8294 
Faróis: estas estruturas de apoio à segurança da navegação tem uma íntima associação com a frequente ocorrência de naufrágios de embarcações na região, demandando a efetiva construção destas torres de sinalização.

A região que engloba a Praia de Naufragados (município de Florianópolis), a Ponta do Papagaio e Praia do Sonho (município de Paulo Lopes) é considerada um santuário de embarcações naufragadas. Isso ocorre em virtude da geografia acidentada do leito marinho que fazia com que boa parte das embarcações que ali trafegavam, nos séculos XVI e XVII, viesse a naufragar (FARIAS et al, 2011: 126).

Tais episódios trágicos tem um grande valor histórico e arqueológico. A historiografia indica que na Baía Sul da llha de Santa Catarina teriam ocorrido mais de dez naufrágios, próximos a "Ponta dos Naufragados", nos mais distintos períodos históricos. Entre estes naufrágios, destacam-se os atribuídos aos navegadores Solís (1516), Caboto (1526) e Diego Flores de Valdés e Pedro Sarmiento de Gamboa (1583), entre outros (FARIAS et al, 2011: 133).

Em 1753 naufragaram no extremo sul da llha duas embarcações que traziam 250 Açorianos para o Rio Grande do Sul; destes, sobreviveram apenas 77, e parte deles passou a viver ali. Esta seria a origem do nome do Farol de Naufragados. Foi construído num maciço de 30 metros, totalizando 42,6 metros acima do mar e seu alcance atual é de 18 milhas, concluído em 04 de novembro de 1860, e inaugurado em 03 de maio de 1861. O Farol da Fortaleza de Anhatomirim: marcava a entrada norte, mas tinha um setor de visibilidade restrito. O Farol da Ilha do Arvoredo (27 17,74S / 48 21,37W), com altitude de 90m com alcance de 24M; as obras iniciaram-se em 1878, sendo inaugurado em 14 de março de 1883. Outros Faróis e Faroletes na Ilha de Santa Catarina e entornos: da Ilha da Galé (2791 S $04824 \mathrm{~W})$, das Ilhas dos Moleques do Sul $(2750,7 \mathrm{~S}$ - 04825,7W), da llha de Coral (2756,0S - 04832,6W), da llha dos Cardos (1,4M a NNW da ponta dos Naufragados), da Ponta da Galheta (no canal de acesso a Lagoa da Conceição), da Ilha de Anhatomirim, da a ilha de Ratones Pequeno (DHN, 2013).

\section{Considerações Finais}

Ao longo de cada uma das etapas políticas, econômicas e culturais, os condicionantes geopolíticos e ambientais teriam determinado formas e intensidades de utilização dos espaços e recursos naturais, por meio de atividades socioeconômicas preponderantes. No período Pré-

(C) Rev. Arqueologia Pública \begin{tabular}{l|l} 
Campinas, SP & v.9
\end{tabular} No.(11) p.93-104 suplemento ISSN 2237-8294 
Colonial, predominaram atividades de fundeio e atracadouro, e de reabastecimento; no período Colonial, destacam-se a defesa (fortalezas militares) e ocupação (imigração açoriana), bem como a transição entre a produção de subsistência e a produção comercial e exportação. $\mathrm{Na}$ etapa das Guerras Regionais, mantém-se basicamente esta produção comercial e exportação portuária. No período entre as Grandes Guerras, inicia-se a queda progressiva da produção comercial e exportação, bem como da atividade portuária regional, com a alavancagem da atividade de cidade administrativa e o esboço da atividade turística. Na etapa do Pós-Guerra, ambas as funções, de cidade administrativa e atividade turística, são muito incrementadas, eclipsando outras atividades pretéritas. Em que pesem os ganhos econômicos gerados pelas mesmas, o grande passivo socioambiental decorrente das expressivas transformações sobre a estrutura e função dos ecossistemas regionais recomenda o (re) planejamento do modelo de desenvolvimento da llha de Santa Catarina, de modo a se evitar a armadilha recursiva de exaustão das fontes geradoras de riqueza e bem estar para as comunidades locais.

No conjunto, as atividades analisadas da llha de Santa Catarina (portuária, faroleira, militar e baleeira) apresentam uma série de condicionantes geoambientais similares, complementares e cumulativos. Suas necessidades estratégicas aproximam-nas das baías e enseadas, com a proximidade de mirantes naturais para a vigilância e a caça; o conhecimento do sistema de correntes marinhas e dos ventos orientava a disposição física no terreno das construções, edificadas com base nos materiais disponíveis nos ambientes do entorno. Como as suas respectivas infraestruturas situam-se sobre a linha de costa, estão diretamente expostas e são beneficiadas, funcionalmente, pela proximidade com o ambiente marinho, embora isso exija maiores cuidados nas técnicas construtivas e nos materiais empregados, pelo alto grau de depreciação provocado pelas ondas, correntes, fluxo de sedimentos e pela maresia.

Tais atividades, quando de sua instalação, tiraram o melhor proveito das características naturais do território, dos recursos e do domínio tecnológico então disponível. Hoje, muitas destas atividades foram substituídas, mas há de reconhecer-se que foram pensadas e implantadas seguindo uma lógica, a qual se aproxima do conceito idealista de sustentabilidade.

\section{Referencias}

\begin{tabular}{|l|l|l|l|l|l|l|}
\hline (C Rev. Arqueologia Pública & Campinas, SP & v.9 & No.(11) & p.93-104 & suplemento & ISSN 2237-8294 \\
\hline
\end{tabular} 
ALMEIDA, Caroline Soares de. Final de Década de 1920 em Florianópolis: a construção do "Miramar" e a urbanização da cidade. Revista Santa Catarina em História (Florianópolis: UFSC) V1, N1: 22-29, 2008.

\section{AMARAL, Maria M. V. Relatório Preliminar do Diagnóstico Técnico Arqueológico das Obras de Infraestrutura no Largo da Antiga Alfândega. Florianópolis: Museu Universitário/UFSC, mai./ago.1992.}

BERGER, Paulo (Org.). Ilha de Santa Catarina: relatos de viajantes estrangeiros nos séculos XVIII e XIX (2 $2^{a}$ ed.). Florianópolis: Ed. FUSC / Assembléia Legislativa, 1984 (334 p).

CARUSO, Marilea Martins Leal. O Desmatamento da Ilha de Santa Catarina: de 1500 aos dias atuais. Florianópolis: Ed. UFSC, 1983 (160 p).

COMERLATO, Fabiana. Retrospectiva da Arqueologia Histórica em Santa Catarina. In: V Congresso Internacional de Estudos Ibero-Americanos, 2003, Porto Alegre.

COMERLATO, Fabiana. Relatório Final da Prospecção Arqueológica em Residências Oitocentistas do Conjunto Histórico da Praça XV. Florianópolis, agosto 1999.

DESTERRO HOJE. Comparações de imagens antigas e atuais. Florianópolis, SC, 2014. Disponível em: http://www.desterrohoje.com.br/index.php/group-holder/centro/ponte-hercilioluz/ponte-hercilio-luz/estaleiro-arataca--ponte-hercilio-luz-1940-2012.html (acesso em: 09 Dezembro 2014).

DHN. Roteiro Costa Sul. Rio de Janeiro: Diretoria de Hidrografia e Navegação. Ministério da Marinha, 2013. Disponível em: http://www.mar.mil.br/dhn/chm/boxpublicacoes/publicacoes/rotcs/rot-cs-completo.pdf (acesso em: 03 Março 2015).

ESPÍNDOLA, Ariana Moreira. A Vida Rural na Freguesia do Ribeirão da llha no Século XIX. Revista Santa Catarina em História (Florianópolis: UFSC), V1, N2: 73-85, 2010.

FARIAS, Deisi Scunderlick Eloy; CORREA, Flávio; DEMATHÉ, Alexandro; GUIMARÃES, Geovan Martins; GERMMER, Bruno Enrique; CORREA, Gabriel. Projeto Resgate Barra Sul: pesquisa arqueológica subaquática no sul de Florianópolis, SC. Navigator, 16: 120-135, 2011.

FOX, Jefferson; SURIANATA, Krisnawati; HERSHOCK, Peter; PRAMONO, Albertus Hadj. O Poder de Mapear: efeitos paradoxais das tecnologias de informação espacial (pp: 71-84). In: ACSELRAD, Henri (Org.). Cartografias Sociais e Território. Rio de Janeiro: UFRJ Universidade Federal do Rio de Janeiro, IPPUR - Instituto de Pesquisa e Planejamento Urbano e Regional, 2008. Coleção Território, Ambiente e Conflitos Sociais, v1 (168 p).

GOULARTI FILHO, Alcides. Portos, Ferrovias e Navegação em Santa Catarina.

Florianópolis: Editora da UFSC - Universidade Federal de Santa Catarina, 2013 (324 p).

MUSSOLINI, Gioconda. Aspectos da cultura e vida social no litoral brasileiro. Revista de Antropologia, São Paulo, 01 (02): 81-97, dez. 1953. 
PÁDUA, José Augusto. As Bases Teóricas da História Ambiental. Estudos Avançados, 24 (68): 81-101, 2010.

POLETTE, Marcus; REBOUÇAS, Gabriel Nunes Maia; FILARDI, Ana Carla Leão; VIEIRA, Paulo Freire. Rumo à Gestão Integrada e Participativa de Zonas Costeiras no Brasil: Percepções da Comunidade Científica e do Terceiro Setor. Gestão Costeira Integrada (Itajaí), 05 (04): 43-48, 2006.

REIS, Almir Francisco. Ilha de Santa Catarina: permanências e transformações. Florianópolis: Ed. UFSC (Coleção Urbanismo e Arquitetura da Cidade), 2012 (284 p).

SANTOS, Fabíola Martins. Uma Análise Histórico-Espacial do Setor Hoteleiro no Núcleo Urbano Central de Florianópolis, SC. Dissertação de Mestrado (PPG. Turismo e Hotelaria). Balneário Camboriú: UNIVALI - Universidade do Vale do Rio Itajaí, 2005 (189 p).

SCHMITZ, Paulo Clóvis. Movimento quer reconstruir atracadouro da Ponta do Sambaqui. Jornal Notícias do Dia (Florianópolis, SC), 21-22 Junho 2014 (pp: 04-05).

$\mathrm{SCHUCH}$, Edmara. A Arqueologia vai a Cidade: proposta de zoneamento arqueológico para o centro de Florianópolis. Trabalho de Conclusão de Curso (Bacharelado e Licenciatura em História). Florianópolis: UDESC - Universidade do Estado de Santa Catarina, 2010 (96 p).

TESSLER, Moysés Gonzalez; GOYA, Samara Cazzoli. Processos Costeiros Condicionantes do Litoral Brasileiro. Revista de Geografia da USP, 17: 11-23, 2005.

TONERA, Roberto. Fortalezas da llha de Santa Catarina: criação, abandono, restauração e revitalização. In: Anais do $4^{\circ}$ Congreso Internacional sobre Fortificaciones (Alcalá de Guadaíra, 05 a 10 de marzo de 2007), p. 149-164, ilus. 2008.

VEIGA, Eliane Veras. Florianópolis: memoria urbana. Coleção Memoria de Florianópolis, N4. Florianópolis: Ed. UFSC - Fundação Franklin Cascaes, 1993 (390 p).

YIN, R. K. Estudo de caso: planejamento e métodos. 3. ed. Porto Alegre: Bookman, 2005.

\begin{tabular}{|l|l|l|l|l|l|l}
\hline @ Rev. Arqueologia Pública & Campinas, SP & v.9 & No.(11) & p.93-104 & suplemento & ISSN 2237-8294 \\
\hline
\end{tabular}

